\title{
Wireless Connectivity Predicaments in GSM-based AMR System: An Empirical Research
}

\author{
S.H. Suliman, W. Hashim, A.F. Ismail, A.S. Yahya, M.H. Khairolanuar, M.S.Sauti
}

\begin{abstract}
The convergence of Global System for Mobile Communication (GSM) and Information Communication Technology (ICT) allows the mobile and wireless application to be implemented in Automatic Meter Reading (AMR) system. In addition to the advancement of cellular technology and spectrum refarming, GSM-based AMR system is continuously facing propagation challenges that affect the stability of wireless connectivity. A field study was conducted to investigate the real reasons for having predicaments in coverage behaviour introduced by GSM-based AMR system for three local Internet Service Providers (ISPs) in Malaysia. The main objective of this study is to verify signal coverage performance at identified AMR locations that were reported having signal lost. We have categorized the challenges and depicted the signal quality readings that show signal performances for different service providers. The outcomes form the basis for our future development of cognitive network selection prototype for utility (gas, electricity, water) companies wireless communication smart grid.
\end{abstract}

Keywords: AMR, cognitive selection mechanism GSM modem, RSSI, signal quality

\section{INTRODUCTION}

AMR is a technology that automatically collects ener-gy consumption data from customer metering devices to a specific utility database for billing purposes. AMR trans-forms the conventional manual meter reading methods which suffer from a wide variety of disadvantages such as manpower and transportation cost [1]-[3] Obviously, AMR reduces human intervention in meter reading and manage-ment processes since the wireless modem is incorporated for transmitting data from meter to the billing department at a regular interval [4]. Figure 1 illustrates basic network architecture of a GSM-based AMR system.

GSM is a digital cellular technology used for trans-mitting

Revised Version Manuscript Received on 10, September 2019.

S.H. Suliman, Institute of Informatics \& Computing in Energy; Universiti Tenaga Nasional, Jalan Ikram-Uniten, 43000 Kajang, Selangor, sitihusna@uniten.edu.my

W. Hashim, Institute of Informatics \& Computing in Energy; Universiti Tenaga Nasional, Jalan Ikram-Uniten, 43000 Kajang, Selangor, Malaysia

A.F. Ismail, Dept. of Elec. \& Comm. Eng., International Islamic

A.S. Yahya, Institute of Informatics \& Computing in Energy; Universiti Tenaga Nasional, Jalan Ikram-Uniten, 43000 Kajang, Selangor, Malaysia

M.H. Khairolanuar, Dept. of Elec. \& Comm. Eng., International

M.S.Sauti, Tenaga Nasional Berhad ICT Devison Malaysia, E-mail: sitihusna.sulaiman@yahoo.com University of Malaysia, Gombak, Selangor, Malaysia Islamic University of Malaysia, Gombak, Selangor, Malaysia

mobile voice and data services. GSM-900 and GSM-1800 are used in most parts of the world with uplink and downlink values as described in Table 1 [5]. The amount of data that has to be sent is quite low, ranging from only several bytes to Kbytes depending on the time performing such data collection task, peak or non-peak. With demanding low bit rates [1]. AMR system utilizes low power radio frequency (RF) communication in GSM net-work, transmitting meter readings to a remote receiver [6].

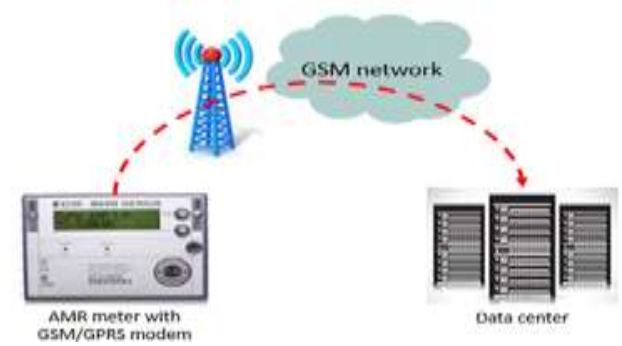

Figure 1. AMR network architecture

Table 1: Uplink and Downlink for GSM

\begin{tabular}{|l|l|l|l|}
\hline $\begin{array}{l}\text { GSM } \\
(\mathrm{MHz})\end{array}$ & Uplink (MHz) & $\begin{array}{l}\text { Downlink } \\
(\mathrm{MHz})\end{array}$ \\
\hline 900 & & $890-915$ & $935-960$ \\
\hline 1800 & & $1710-1785$ & $1805-1880$ \\
\hline
\end{tabular}

The rapid development of GSM technology has made wireless communication in AMR system more reliable and feasible [5]. However, a stable, reliable and less fluctuate wireless connection is crucial to ensure that all readings are successfully sent to the data center for billing department utilization. An often time, wireless connectivity in AMR is facing several challenges that affect such desirable features. Uncertainties in wireless connectivity can eventually lead to the loss and error of quality data while transmitting. The utility company may face a monetary lost if they are unable to charge customer accurately.

Having a communication device that is wirelessly con-nected are susceptible to the risks such as communication lost, call drop-outs and out-of-coverage signalling especial-ly on collecting real-time data in short period of an interval [7]. It is hard to confirm that the selected provider can sus-tain a good connectivity at all time. This is even more chal-lenging when the AMR device is relying on single network connectivity since should anything happen to this network the AMR meter will only resume operation once the only network is back to normal.

The new development area 
is a risk too. Business wise, telecommunication provider may refuse to install a new base

station in this location due to less population of poten-tial customers. It is difficult to justify for the return of in-vestment on the high infrastructure cost to provide good connectivity especially at very challenging geographical terrains such as the top of the hill, ravines, and archipelago of islands. In addition to this, an AMR location in a base-ment area is an issue too. Connection instability due to building penetration effects is one of the reasons for such predicament [8].

Rural areas and smaller cities may also encounter lim-ited telecommunications infrastructure especially those which are remote and isolated [9]. The key challenges for providing communication services in rural areas are driven by technological and economic consideration. High cost is needed to set up the communication infrastructure. Figure 2 summarizes these elements in AMR wireless connectivity that motivate our studies to further investigate these predic-aments through conducting preliminary coverage analysis activities at specific reported AMR locations.

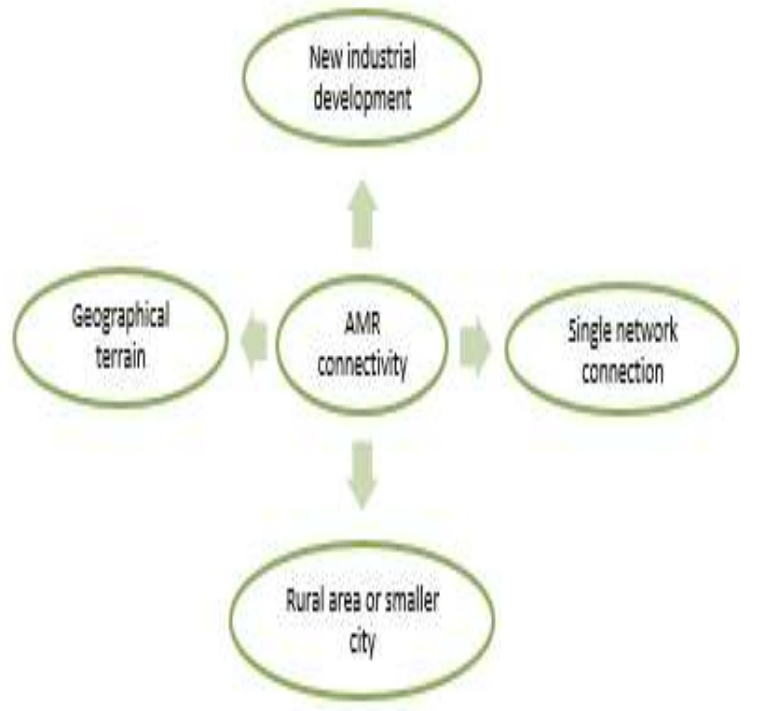

Figure 2: Challenges in AMR Wireless Connectivity

The coverage analysis activities were conducted at AMR location to identify the signal strength value $(\mathrm{dBm})$ based on three local service providers in Malaysia such as Celcom, Maxis, and Digi. The reason for these selections is due to their wide coverage as compared to other local ISPs.

\section{RECEIVED SIGNAL STRENGTH INDICATOR (RSSI)}

RSSI is a basic parameter to measure the signal strength of a communication signal. The value of RSSI varies due to terrain and cultural (building) obstruction or impairments to signal propagation as well as to the distance between the radio telephone and the base station or cell site [10]. Table 2 represents the RSSI value vs. signal quality. The higher the RSSI number, the stronger the signal. Thus, when the RSSI value is nearing zero, the better the signal, however, this is unachievable.

Table 2: RSSI Table

\begin{tabular}{|l|l|}
\hline RSSI $(\mathrm{dBm})$ & Signal Strength \\
\hline$>-70$ & Excellent \\
\hline-70 to -85 & Good \\
\hline-86 to -100 & Fair \\
\hline$<-100$ & Poor \\
\hline-110 & No signal \\
\hline
\end{tabular}

\subsection{Field Measurement}

Signal analyzer (Keysight NB3408) with Omni-LOG90200 antenna was used to measure the signal level for three main service providers as shown in Figure 3. Table 3, on the other hand represents spectrum arrangement for service providers retrieved from Malaysia Communications and Multimedia Commission (MCMC) website .The objectives of the site measurement are to verify signal cov-erage and to analyze signal performance for telecommuni-cation main service providers. The measurement was con-ducted by the following procedures.

a.The scanned data is saved for record and further analysis.

b.The availability of other services signal (Maxis and DiGi) is measured.

c.The scanned data is saved for comparison purposes.

d.Step a,b and c are repeated for UMTS (3G) and LTE (4G) coverage.

e.The results are analyzed and compared to find the signal strength performance.

The availability of Celcom GSM-900 and GSM-1800 signal coverage is verified by using spectrum analyzer at the site location. Figure 4 illustrates the process flow.

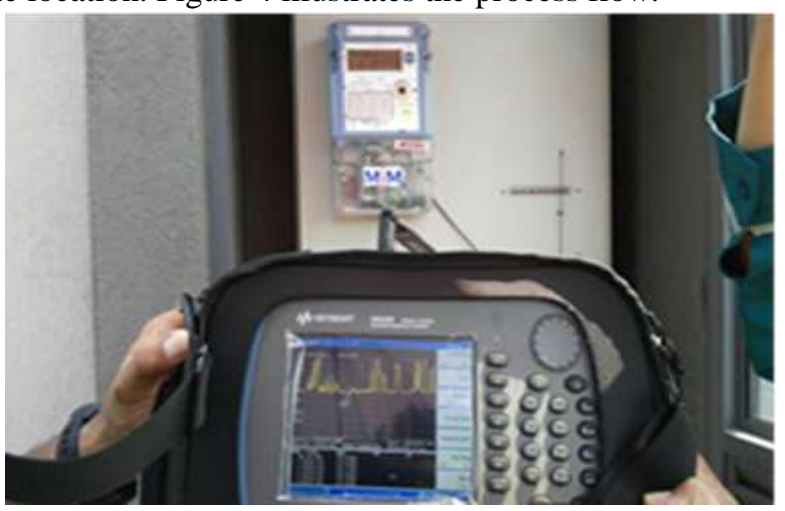

CUNITEN

Figure 3: Portable spectrum analyzer 


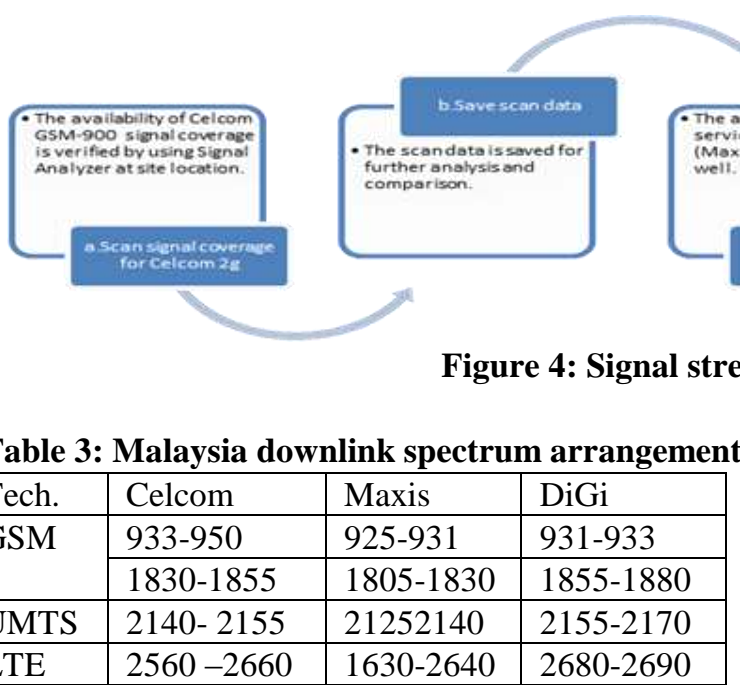

Figure 5, shows three different sites locations under study that can be classified as the rural area, geographical terrain, and new industrial development.

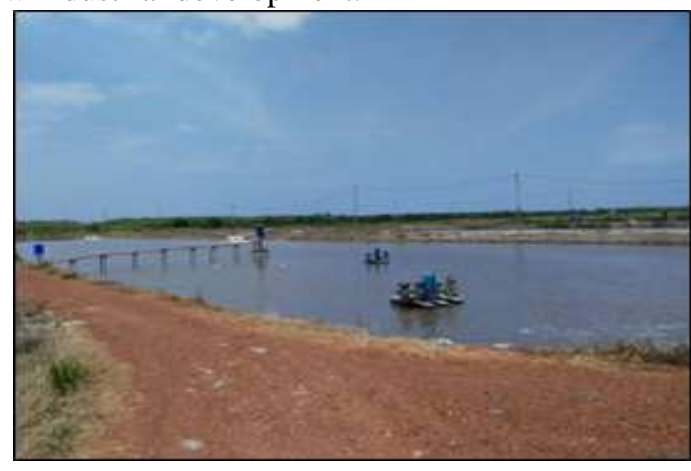

Figure5(a) Rural area

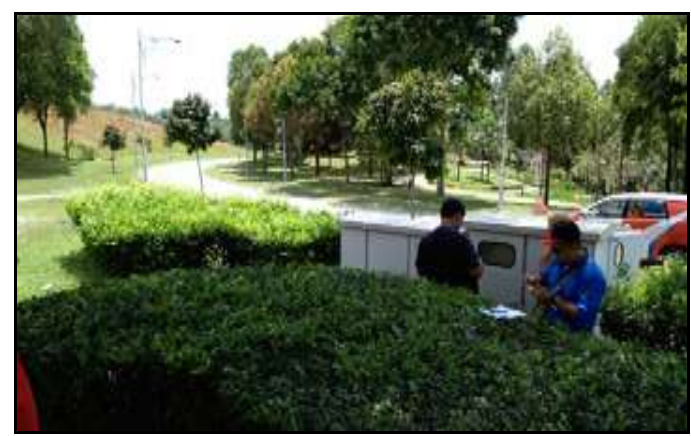

Figure 5(b) Geographical Terrain

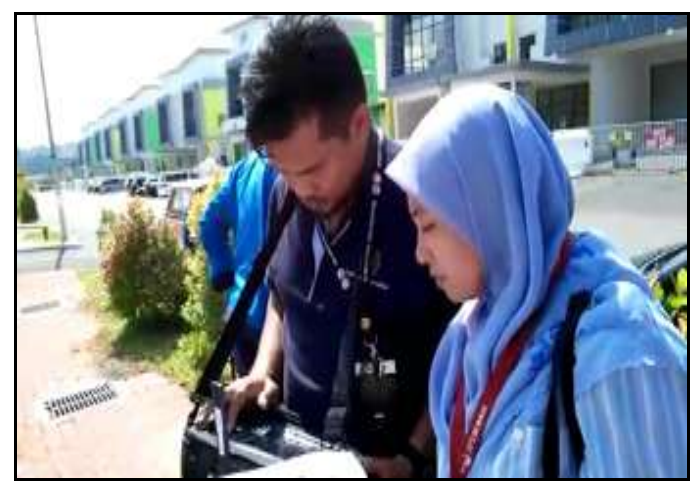

Figure 5(c) New industrial development

\section{RESULTS AND DISCUSSION}

Table 4 represents the value of signal strength acquired from the signal analyzer for the three main service provid-ers graph as shown in Figure 6 (a). Based on the graph, it can be concluded that Maxis offers reliable signal strength with more than $19.54 \mathrm{dBm}$ higher than other service pro-viders for the $2 \mathrm{G}$ network at $900 \mathrm{MHz}$ frequency range. For $1800 \mathrm{MHz}$ DiGi offers more prominent signal strength with more than $18.13 \mathrm{dBm}$ higher than the rest of the two. For the $3 \mathrm{G}$ network, Celcom offers reliable signal strength with just above $0.06 \mathrm{dBm}$ higher than other service providers. While for the $4 \mathrm{G}$ network, Celcom offers reliable signal strength with more than $2.6 \mathrm{dBm}$ higher than other service providers.

Table 4: Signal strength measurement (Semenyih - new development area)

\begin{tabular}{|l|l|l|l|l|}
\hline & $\begin{array}{l}\text { GSM-90 } \\
0 \\
(\mathrm{dBm})\end{array}$ & $\begin{array}{l}\text { GSM-1800 } \\
(\mathrm{dBm})\end{array}$ & $\begin{array}{l}\text { UMTS } \\
(\mathrm{dBm})\end{array}$ & $\begin{array}{l}\text { LTE } \\
(\mathrm{dBm})\end{array}$ \\
\hline Celcom & -74.77 & -100.78 & -54.44 & -94.13 \\
\hline Maxis & -55.23 & -72.74 & -63.63 & -97.03 \\
\hline Digi & -98.51 & -54.61 & -54.50 & -98.69 \\
\hline
\end{tabular}

Table 5: Signal strength measurement results (Shrimp har-vester - rural)

\begin{tabular}{|l|l|l|l|l|}
\hline & $\begin{array}{l}\text { GSM-900( } \\
\mathrm{dBm})\end{array}$ & $\begin{array}{l}\text { GSM-1800(d } \\
\mathrm{Bm})\end{array}$ & $\begin{array}{l}\text { UMTS(d } \\
\mathrm{Bm})\end{array}$ & $\begin{array}{l}\text { LTE(dB } \\
\mathrm{m})\end{array}$ \\
\hline Celcom & -66.09 & -71.12 & -77.41 & -81.71 \\
\hline Maxis & -68.99 & -68.85 & -62.78 & -81.86 \\
\hline Digi & -85.57 & -69.47 & N/A & -98.69 \\
\hline
\end{tabular}

Following the comparison of Figure 6 (b), we can ob-serve the average performance of Celcom is ranging above $-80 \mathrm{dBm}$ to $-60 \mathrm{dBm}$ for $2 \mathrm{G}, 3 \mathrm{G}$, and $4 \mathrm{G}$ respectively. The measurement for DiGi shows a poor performance in con-trast to Maxis.

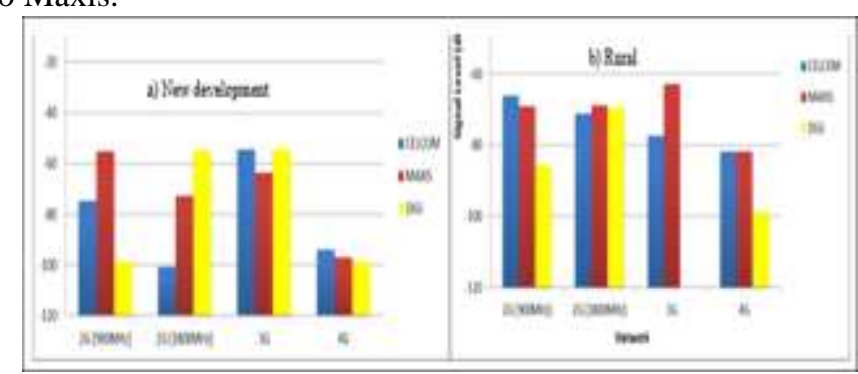

Figure 6: Signal strength comparison between new development and rural area

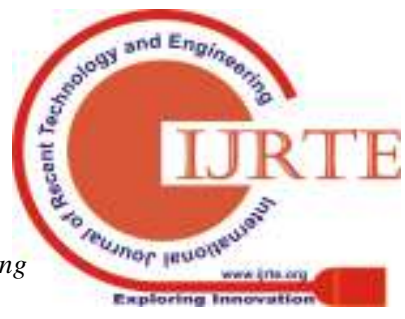




\section{CONCLUSION}

We have conducted coverage analysis studies at specific AMR locations to verify signal coverage performance of an ISP. From the outcome, having more than one telecommunication providers could be a better solution to encounter instability in wireless connection. In the future $3 \mathrm{G}$ and $4 \mathrm{G}$ connection can be used to carry information with more speed as compared to other GSM modules.

\section{ACKNOWLEDGEMENTS}

We would like to state our outmost gratitude to the TNB for sponsoring our project based on TNB seeding fund grant U-TI-RD-17-04.

\section{REFERENCES}

1. Sarangle, Rahul Ganesh, Uday Pandit, Khot Prof, and Jayen Modi. 2012. "Gsm Based Power Meter Reading" 1 (4): 273-79.

2. Rashdi, Adnan, Rafia Malik, Sanam Rashid, Anam Ajmal, and Sulaiman Sadiq. 2013. "Remote Energy Monitoring, Profiling and Control Through GSM Network." Arabian Journal for Science and Engineering $\quad 38 \quad$ (11): $3249-57$. doi:10.1007/s13369-012-0432-x.

3. Abdollahi, Ali, Marjan Dehghani, and Negar Zamanzadeh. 2007. "SMS-Based Reconfigurable Automatic Meter Reading System.” Proceedings of the IEEE International Conference on Control Applications, no. October: 1103-7. doi:10.1109/CCA.2007.4389381.

4. Hiew, Yik Kuan, Norazizah Mohd Aripin, and Norashidah Md Din. 2015. "Performance of Cognitive Smart Grid Communication in Home Area Network." ISTT 2014 - 2014 IEEE 2nd International Symposium on Telecommunication Technologies, 417-22. doi:10.1109/ISTT.2014.7238247.

5. Sauter, Martin. 2011. "From GSM to LTE: An Introduction to Mobile Networks and Mobile Broadband" John Wiley \& Sons, West Sussex, United Kingdom

6. "Reading Article: Case Study of the First Large AMI Project in Poland, Written by Maxim Granatiri and Nicolae Tarlapan. ADD GRUP.” 2017. Accessed May 23.

http://www.energetica-international.com/articles/casestudy-of-the-first-large-ami-project-in-poland.

7. Liting, Cao, Tian Jingwen, and Zhang Dahang. 2006. "Networked Remote Meter-Reading System Based on Wireless Communication Technology." Proceedings of IEEE ICIA 2006 - 2006 IEEE International Conference on Information Acquisition, 172-76. doi:10.1109/ICIA.2006.305989.

8. "GSM (Global System for Mobile Communications) Is an Open, Digital Cellular Technology Used for Transmitting Mobile Voice and D." 2017. Accessed May 23. http://ecee.colorado.edu/ ecen4242/gsm/index.htm.

9. Christian, H, Christoph Ide, and Christian Wietfeld. 2014. "Coverage and Capacity Analysis of Wireless M2M Technologies for Smart Distribution Grid Services." 2014 IEEE International Conference on Smart Grid Communications, 368-73.

10. Bala Poline 2000 "Potential Users Profile and Existing Communication Pattern among the Rural Community of Bario A Need Analysis for the Development of a Telecentre."
11. "Industrial Networking Solutions Tips and Tricks: Making Sense of Signal Strength/Signal Quality Readings for Cellular Modems.” 2017. http://blog.industrialnetworking.com/2014/04/makingsense-of-signal-strengthsignal.html. 